\title{
Comparison between vaginoscopy and traditional technique of hysteroscopy under local anesthesia for operative approach
}

\author{
Yasemin ÇEKMEZ*, Doğa ÖCAL ${ }^{* *}$, Vakkas KORKMAZ***, Tuncay KÜÇÜKÖZKAN**
}

\section{SUMMARY}

Objective: To compare vaginoscopy with traditional technique of hysteroscopy combined with local anesthesia for surgical procedures in terms of patient compliance and ease of procedure.

Material and Method: A total of 98 women who were scheduled for operative hysteroscopy were divided into two groups: Group 1 (vaginoscopy), Group 2 (traditional technique with local anesthesia). Patient compliance was assessed by using a Visual Analog Scale (VAS) at five different time points as follows: before placement of speculum, phase 1 (baseline pain perception); after placement of the speculum, phase 2; after grasping with tenaculum, phase 3; during hysteroscopy, phase 4; and 5 min after the procedure, phase 5.VAS-4 reflected the compliance of patients. We determined the ease of the procedure by employing Likert-type scale to clinicians.

Results: VAS-2 scores were statistically higher in Group 2 than Group $1(P=0.001)$. There were no significant differences between VAS-1,VAS-3 and VAS-5 scores. VAS-4 scores were statistically higher in Group 1 than Group $2(P=0.001)$ Likert-type scale scores were statistically higher in Group $2(P<0.001)$, but the procedure time was longer in Group 1 than Group $2(P=0.001)$.

Conclusion: Usage of tenaculum and speculum decreases the compliance of the patient although they help to facilitate the procedure. However based on our study, we suggest that traditional technique combined with local anesthesia may be better than vaginoscopy for operative procedures in terms of patient compliance and ease of the procedure.

Key words: Vaginoscopy, hysteroscopy, anesthesia

\section{INTRODUCTION}

Hysteroscopy is widely accepted as the standard endoscopic modality for investigation of the uterine cavity ${ }^{(1)}$. It is a minimally invasive approach and also provides an opportunity to evaluate intrauterine pathologies and to take biopsies at the same time ${ }^{(2)}$. Interventions with hysteroscopy are now being performed in the office setting with the development of more advanced hysteroscopic devices. Patient's compliance is important for a successful office hysteroscopic evaluation without anesthesia.

Like most other gynecological office procedures including endometrial sampling, hysterography, intrauterine device insertion, and intrauterine insemination, hysteroscopy also often requires the application of a speculum to visualize the cervix and a singletooth tenaculum to fixate the cervix, straighten the cervico-uterine angle, provide counter-traction and facilitate the procedure. However enlarging the vagina with a speculum and grasping the cervix with a tenaculum can be painful for the patient ${ }^{(3)}$. The pain and discomfort felt by the patients may complicate the process.Application of local anesthesia to the uterine cervix may decrease pain and facilitate the procedure especially for operative hysteroscopy. 
Vaginoscopy is an alternative method for performing hysteroscopy without the need for insertion of a vaginal speculum to view the cervix or cervical instrumentation to grasp and steady the cervix.It is known as gold standart technique for outpatient hysteroscopic approaches ${ }^{(4)}$.

In this trial we aimed to compare the vaginoscopy and traditional technique of hysteroscopy combined with local anesthesia for operative hysteroscopy in terms of patient compliance and ease of the procedure. Our primary endpoinrs were VAS scores and secondary endpoints were Likert-type scale scores.

\section{MATERIALS and METHODS}

A total of 182 women in their reproductive ages who were admitted to our outpatient unit for menorrhagia were selected for this prospective trial. After a detailed history and physical examination we offered office hysteroscopy to all subjects. A hundred and twelve subjects were scheduled for operative hysteroscopy for various reasons (polyps, leiomyomas), and 14 of these patients did not give permission and excluded from the study. The remaining 98 patients were included in the study.

The study was a prospective study conducted between June 2013-January 2014 at our department of gynecology. Scientific and ethical approval was received from the institutional review board. All participants gave their written informed consent.

A total of 98 women in their reproductive age in whom operative hysteroscopy planned were randomly (1:1) assigned to two groups: Group 1 (vaginoscopy, no=48) and Group 2 (traditional technique with local anesthesia, no=50).

Patients with positive b-HCG test, stenotic cervical os, acute cervicitis, known history of uterine malignancy, uterine anomalies or leiomyomas, or who had experienced failed office hysteroscopy procedure were excluded from the study. No patient was given misoprostol before the procedure and no routine an- tibiotic prophylaxis was administered. Lidocaine (2 $\mathrm{mg} / \mathrm{kg}$ ) was injected into the cervix of the patients in Group 2 before grasping with the tenaculum. The patients were not informed about the group to which they belonged. Hysteroscopy was performed by a single gynecologist using the same room and table in order to maintain consistency and to limit confounding variables. For hysteroscopic instrumentation Xenon Nova 300 (2 mm optical view) device was used. We used $5 \%$ mannitol for distension. We took biopsies from all patients (for polyps, endometrial thickness and myoma uteri).

The patients were asked to identify their pain according to a visual analog pain scale (VAS, $0=$ no pain; $10=$ worst possible pain) at the following time points: before placement of the speculum, phase 1 (baseline pain perception); after placement of the speculum, phase 2; after grasping with tenaculum, phase 3; during hysteroscopy phase 4 ; and 5 min after the procedure phase 5. VAS-4 reflected compliance of the patient. Scores were measured and recorded. We also measured and recorded the scores of a 5-cm Likerttype scale completed by the clinician $(1=$ very difficult, $5=$ very easy).

Likert scale is a psychometric scale commonly used to score responses in a survey research ${ }^{(5)}$. VAS scale is a pain scale which measures patient's pain intensity or other features which are based on self-report, observational (behavioral), or physiological data ${ }^{(6)}$.

\section{Statistical analysis}

Statistical analysis was performed with SPSS 12.0 software (IBM, Chicago, IL, USA). Data were expressed as mean \pm standard deviation. Chi-square or Fisher's exact test was used to compare categorical variables, and the Wilcoxon Rank Sum test was used to compare continuous variables. A $\mathrm{P}$ value $<0.05$ was considered statistically significant. Ordinal data (VAS, Likert-type scale) were analyzed by using Kruskal-Wallis test or Mann-Whitney U test. Time dependent data were analyzed by Friedman test. 


\section{RESULTS}

The characteristics of the groups are summarized in Table 1. There were seven failed procedures (7/300, $2.33 \%$ ). Five were in Group 1 and 2 were in Group 2 . There was no significant difference between the groups for failure of the hysteroscopy $(\mathrm{P}>0.05)$. We defined inability to access the uterine cavity as failed procedure. These failures were due to pain in four patients and complicated procedures in 3 patients.

Table 1. Characteristics of patients in two groups.

\begin{tabular}{lccc}
\hline & $\begin{array}{c}\text { Group 1 } \\
\text { (vaginoscopy) } \\
\text { No=48 }\end{array}$ & $\begin{array}{c}\text { Group 2 } \\
\text { (traditional method) } \\
\text { No=50 }\end{array}$ & P values \\
\hline Age (years) & $41.8 \pm 10.1$ & $42.6 \pm 9.3$ & $\mathrm{P}>0,05$ \\
$\begin{array}{l}\text { Number of vaginal } \\
\text { deliveries }\end{array}$ & $3 \pm 0.1$ & $2.8 \pm 0.2$ & $\mathrm{P}>0,05$ \\
Endometrial surgery & & & \\
(curettage and/or & & & \\
hysteroscopy) & 40 & 45 & $\mathrm{P}<0,05$ \\
Absent & 8 & 5 & $\mathrm{P}<0,05$ \\
Present & & & \\
Educational & 10 & 12 & $\mathrm{P}>0,05$ \\
achievement level & 10 & 14 & $\mathrm{P}<0,05$ \\
Absent & 12 & 10 & $\mathrm{P}>0,05$ \\
Primary school & 12 & 8 & $\mathrm{P}<0,05$ \\
Secondary school & 4 & 6 & $\mathrm{P}>0,05$ \\
High school & & & \\
University & 34 & 40 & $\mathrm{P}<0,05$ \\
Dyspareunia & 14 & 10 & $\mathrm{P}<0,05$ \\
Absent & & & \\
Present & 40 & 9 & $\mathrm{P}>0,05$ \\
Dysmenorrhea & 8 & & $\mathrm{P}>0,05$ \\
Absent & & & \\
Present & & & \\
\hline
\end{tabular}

The means of VAS, Likert-type scale, procedure time and the differences between the groups are presented in Table 2. VAS-2 and VAS-3 were same with VAS-1 in patients who belonged to Group 1.VAS-2 scores were statistically higher in Group 2 than Group 1 $(\mathrm{P}=0.001)$. There was no significant difference between VAS-1, VAS-3 and VAS-5 scores. VAS-4 scores were statistically higher in Group 1 than Group 2 $(\mathrm{P}=0.001)$. Likert-type scale scores were statistically higher in Group $2(\mathrm{P}<0.001)$, but the procedure time was longer in Group 1 than Group $2(\mathrm{P}=0.001)$.

Table 2. Comparison between VAS-Likert scores and procedure time.

\begin{tabular}{lccc}
\hline & $\begin{array}{c}\text { Group 1 } \\
\text { (vaginoscopy) }\end{array}$ & $\begin{array}{c}\text { Group 2 } \\
\text { (traditional technique) }\end{array}$ & P values \\
\hline VAS-1 & $0.1 \pm 0.4$ & $0.1 \pm 0.6$ & \\
VAS-2 & $0.1 \pm 0.4$ & $2.4 \pm 1.8 *$ & $\mathrm{P}>0,05$ \\
VAS-3 & $0.1 \pm 0.4$ & $0.2 \pm 0.3$ & $\mathrm{P}<0,05$ \\
VAS-4 & $6.2 \pm 1.5 *$ & $5.2 \pm 2.3$ & $\mathrm{P}>0,05$ \\
VAS-5 & $2.1 \pm 1.2$ & $2.4 \pm 2$ & $\mathrm{P}<0,05$ \\
Likert scale & $4 \pm 0.9$ & $4.8 \pm 1.4 *$ & $\mathrm{P}>0,05$ \\
Time of procedure & $6.4 \pm 1.52^{*}$ & $5.8 \pm 1.4$ & $\mathrm{P}<0,05$ \\
(min) & & & $\mathrm{P}<0,05$ \\
\hline
\end{tabular}

$* P<0.05$, Group 1 vs. Group 2

Parameters such as educational status, history of dysmenorrhea and dyspareunia, and parity which may affect patients' pain perception and their association to VAS, Likert-type scale, and the time of the procedure were evaluated and shown in Table 3. High educational status was associated with higher VAS-2 and VAS-3 level which was not anticipated. The presence of history of dysmenorrhea was associated with higher levels of VAS-2, 3 and $4(\mathrm{P}<0.001)$. Multiparous patients had lower VAS- 2 and 3 scores $(\mathrm{P}=0.018$, 0.012 , respectively).

Table 3. Effect of educational status, dysmenorrhea, dyspareunia and parity on VAS-Likert scale scores and procedure time.

\begin{tabular}{|c|c|c|c|c|c|c|c|c|c|}
\hline & & VAS-1 & VAS-2* & VAS-3* & VAS-4 & VAS-5 & Likert score & Procedure time (min) & P values \\
\hline \multirow{5}{*}{ Education level } & Absent & $0.2 \pm 0.5$ & $2.3 \pm 1.2$ & $3.4 \pm 1.1$ & $3.5 \pm 0.8$ & $2.5 \pm 0.8$ & $4.3 \pm 1.12$ & $6.2 \pm 1$ & $P>0,05$ \\
\hline & Primary school & $0.2 \pm 0.6$ & $2.3 \pm 0.9$ & $3.3 \pm 1$ & $3.7 \pm 0.8$ & $2.7 \pm 0.4$ & $4.4 \pm 0.45$ & $6.1 \pm 1.2$ & $P>0,05$ \\
\hline & Secondary school & $0.1 \pm 0.8$ & $2.4 \pm 0.5$ & $3.6 \pm 1.2$ & $3 \pm 0.6$ & $2.2 \pm 0.7$ & $4.4 \pm 0.5$ & $5.9 \pm 1.3$ & $P>0,05$ \\
\hline & High school & $0.1 \pm 0.9$ & $2.4 \pm 1$ & $3.7 \pm 0.8$ & $4.5 \pm 0.9$ & $3.5 \pm 0.2$ & $4.6 \pm 1.14$ & $5.9 \pm 1.2$ & $\mathrm{P}<0,05$ \\
\hline & University & $0.1 \pm 0.5$ & $2.5 \pm 0.9$ & $5 \pm 0.5$ & $4.5 \pm 1.2$ & $3.5 \pm 1.2$ & $4.8 \pm 0.6$ & $5.1 \pm 1$ & $\mathrm{P}<0,05$ \\
\hline \multirow[t]{2}{*}{ Dys-menorrhea } & Absent & $0.2 \pm 0.8$ & $2.3 \pm 1.1$ & $3.1 \pm 1$ & $4.3 \pm 0.9$ & $3.3 \pm 0.4$ & $4.6 \pm 0.5$ & $6 \pm 1.4$ & $P>0,05$ \\
\hline & Present & $0.3 \pm 0.6$ & $3.4 \pm 1$ & $5.6 \pm 1.4$ & $5.1 \pm 1.1$ & $3.1 \pm 0.6$ & $4.3 \pm 0.8$ & $6.6 \pm 1.2$ & $\mathrm{P}<0,001$ \\
\hline \multirow[t]{2}{*}{ Dys-pareunia } & Absent & $0.19 \pm 0.5$ & $2.31 \pm 1.2$ & $4.5 \pm 1$ & $3 \pm 1.2$ & $2.7 \pm 0.5$ & $4.4 \pm 0.5$ & $5.9 \pm 1.4$ & $P>0,05$ \\
\hline & Present & $0.2 \pm 0.6$ & $4.6 \pm 0.5$ & $5.2 \pm 0.5$ & $4.1 \pm 1.4$ & $3.1 \pm 1$ & $4.2 \pm 1$ & $7 \pm 2$ & $P<0,05$ \\
\hline \multirow[t]{3}{*}{ Parity } & 0 & $0.2 \pm 0.4$ & $3.2 \pm 0.6$ & $5.6 \pm 0.8$ & $3.5 \pm 1.6$ & $2.5 \pm 0.8$ & $4.4 \pm 0.9$ & $6.6 \pm 1.5$ & $\mathrm{P}>0,05$ \\
\hline & 1 & $0.18 \pm 0.9$ & $2.4 \pm 0.4$ & $4.3 \pm 0.9$ & $2.5 \pm 0.6$ & $2 \pm 0.5$ & $4.7 \pm 1.2$ & $5.9 \pm 1.3$ & $\mathrm{P}>0,05$ \\
\hline & $>1$ & $0.19 \pm$ & $2.1 \pm 0.8$ & $4.2 \pm 0.6$ & $2.4 \pm 0.5$ & $1.4 \pm 0.3$ & $4.7 \pm 1.1$ & $5.9 \pm 1.2$ & $\mathrm{P}=0,018$ \\
\hline
\end{tabular}

*detected for only group 2. 
No acute or subacute complications such as intractable bleeding, tenaculum-related cervical tears, vasovagal reactions due to pain, uterine rupture or infection were seen during the study.

\section{DISCUSSION}

Hysteroscopy can be regarded as the gold standard for the evaluation of the uterine cavity and subsequent detection of intrauterine pathology ${ }^{(7)}$. While the international literature suggests that outpatient hysteroscopy without using any form of analgesia or anaesthesia is a well-tolerated procedure with a high success rate in general, it continues to be considered as an invasive and painful technique by most gynaecologists and patients ${ }^{(8)}$. Indeed, pain experienced during the procedure continues to represent the most common reason for failure, and this can occur even if local anaesthesia is used ${ }^{(9)}$. Although some literature suggests that pain control for hysteroscopy is still unclear, the major obstacle to the successful completion of these outpatient gynecologic procedures is pain management ${ }^{(10)}$. Dilating the vagina with a speculum and grasping the cervix with a tenaculum have painful implications for the patient ${ }^{(3)}$. There are lots of trials in the literature to control pain without the use of pain relief and anesthesia ${ }^{(11)}$. In a prospective randomized trial music was found to be useful as a complementary method to control anxiety and reduce perception of pain during office hysteroscopy ${ }^{(12)}$.

Vaginoscopy, also known as the 'no-touch' technique, is an alternative method for performing hysteroscopy without the need for a vaginal speculum to view the cervix or cervical instrumentation to grasp and steady the cervix ${ }^{(4)}$. This technique has permitted complete elimination of any kind of premedication, analgesia or anaesthesia, making the procedure faster and complication-free for diagnostic investigation ${ }^{(13)}$. But what about operative hysteroscopy? In our trial we compared the vaginoscopy and traditional technique of hysteroscopy combined with local anesthesia for operative hysteroscopy in terms of patient compliance and ease of procedure.
According to our results pain perception is statistically higher in Group 2 according to VAS-2 scores. There were no significant differences between VAS-3 scores which may be caused by the local anesthesia. VAS-4 scores were statistically higher in Group 1 than Group $2(\mathrm{P}=0.001)$. Contrarily, in a trial it is reported that vaginoscopic approach to outpatient hysteroscopy is successful and significantly reduces the pain experienced by patients during the procedure, compared with traditional techniques using a vaginal speculum (4). But in this trial the authors used hysteroscopy for diagnosis rather than operative purposes. This difference may be due to our operative interventions like cutting and ablation.

Based on the results of our trial dysmenorrhea and dyspareunia were associated with higher VAS 2 and 3 scores. This higher scores may be due to undiagnosed focal implants of pelvic endometriosis ${ }^{(14)}$. Our results revealed that high educational status is associated with higher pain perception in this procedure. This was an unexpected finding and as expected, patients with higher vaginal delivery rate have lower pain perception ( $\mathrm{P}=0.018,0.012$, respectively) and Likert-type scale scores were higher in this group. The procedure time was longer in Group 1 than Group 2 $(\mathrm{P}=0.001)$.

Like other factors hysteroscopist's level of experience is also important for compliance and pain perception of patients which was reported in a trial ${ }^{(12)}$. In our trial the procedure was performed by only one gynecologist who had qualification in this regard to maintain consistency and limit confounding variables. Likerttype scale scores were higher in Group 2. This may be due to the real pain reduction of the local anesthesia and placebo effect of the drug.

As a result, we suggest that although vaginoscopic approach has permitted complete elimination of any kind of premedication, analgesia or anaesthesia, making the procedure faster, complication-free for diagnostic investigation, tenaculum and speculum usage help to facilitate the procedure and traditional technique combined with local anesthesia may be better 
than vaginoscopy for operative procedures in terms of patient compliance and ease of procedure. This study provides guidance for clinicians who will decide to perform outpatient operative hysteroscopy.

\section{REFERENCES}

1. Clark TJ, Voit D, Gupta JK, et al. Accuracy of hysteroscopy in the diagnosis of endometrial cancer and hyperplasia: a systematic quantitative review. JAMA 2002;288:1610-1621. http://dx.doi.org/10.1001/jama.288.13.1610

2. Murat D. Jinekolojik onkolojide histeroskopinin yeri. Gülhane Tip Dergisi 2002;44:464-471.

3. Guida M, Di Spiezio Sardo A, Acunzo G, et al. Vaginoscopic versus traditional office hysteroscopy: a randomized controlled study. Hum Reprod 2006;21:323-325. http://dx.doi.org/10.1093/humrep/del298

4. Copper NA, Smith P, Khan KS, et al. Vaginoscopic approach to out patient hysteroscopy:a systematic review of the effect on pain. BJOG 2010;117:532. http://dx.doi.org/10.1111/j.1471-0528.2010.02503.x

5. Şahin DB, Gülleroğlu HD. Examination of the psychometric properties of scale developed through item analysis techniques that are used to select items for Likert-type. Asian Journal of Instruction 2013;1(2):18-28.

6. Chapman CR, Syrjala KL. Measurement of Pain, The Management of Pain, Edit By JJ Bonica $2^{\text {nd }}$ edit. Vol.1, Lea\&Febiger, Philadelphia, London 580, 1991.
7. Koskas M, Mergui JL, Yazbeck C, et al. Office hysteroscopy for infertility: aseries of 557 consecutive cases. Obstet Gynecol Int 2010: 168096. http://dx.doi.org/10.1155/2010/168096

8. Yang $\mathbf{J}$, Vollenhoven B. Pain control in outpatient hysteroscopy. Obstet Gynecol Surv 2002;57:693. http://dx.doi.org/10.1097/00006254-200210000-00023

9. Sharma M, Taylor A, di Spiezio Sardo A Buck L, et al. Outpatient hysteroscopy: traditional versus the 'no-touch' technique. BJOG 2005;112:963.

http://dx.doi.org/10.1111/j.1471-0528.2005.00425.x

10. Tangsiriswatthana TS, US, Lumbiganon $P$, Loapaiboon M. Paracervical local anaesthesia for cervical dilation and uterine intervention. Cochrane Database Syst Rev 2009; Art. No.: CD005056. http://dx.doi.org/10.1002/14651858.CD005056.pub2

11. Issat T, Beta J, Nowica MA, et al. A randomized, single blind, placebo-controlled trial for the pain reduction during the outpatient hysteroscopy after Ketoprofen or intravaginal Misoprostol. J Minim Invasive Gynecol 2014; 23 . pii: S15534650(14)00252-0. http://dx.doi.org/10.1016/j.jmig.2014.04.006.

12. Angioli R, De Cicco Nardone $\mathbf{C}$, Plotti F, et al. Use of music to reduce anxiety during office hysteroscopy: prospective randomized trial. J Mini Invasive Gynecol 2013; 17.pii: S1553-4650(13)00429-9.

http://dx.doi.org/10.1016/j.jmig.2013.07.020

13. Cicinelli E. Diagnostic minihysteroscopy with vaginoscopic approach: rationale and advantages. J Minim Invasive Gynecol 2005;12:396. http://dx.doi.org/10.1016/j.jmig.2005.06.004

14. Garad R, Vancaillie TG, Farrell E. Pelvic pain: a diagnosis in itself. Aust Nurs $J$ 2013;21:36. 